cycline resistant strains. Certainly, some of the clinical features that they describe (reddening of the glans penis, pruritus of the foreskin, vaginal itching) are unusual for chlamydial infections, and the speed with which the dentist developed ocular symptoms and signs is surprising. It would also be surprising if the apparently tetracycline resistant strains were confined to three patients in Rome in early 1985 . Unfortunately, Dr Midulla and colleagues did not provide information on in vitro antibiotic susceptibility. From the information given, it is hardly plausible that the strains would be tetracycline sensitive in vitro. If, by chance, they were then I submit that the paper is based on a false premise because the dose of the tetracyclines and the duration of treatment were sufficient to have caused clinical improvement. Realistically, however, there are only two possible explanations. Either chlamydias were not isolated at all or they were and proved to be resistant in vitro.

If the second explanation is true then the finding is important because it has wide implications for those working in gynaecological, paediatric, and genitourinary medicine and needs greater emphasis than the conclusion by the authors that rifampicin should be used for " $C$ trachomatis infections resistant to commonly used antibiotics." It is to be hoped that they will provide the in vitro data that will resolve this important issue or release the strains so that others may do so.

DAVID TAYLOR-ROBINSON

Division of Sexually Transmitted Diseases,

Medical Research Council
Clinical Research Centre,

Harrow, Middlesex HA1 3UJ

1 Johnson FWA, Spencer WN. Multiantibiotic resistance in Chlamydia psittaci from ducks. Vet Rec 1983;112:208.

AUTHORS' REPLY - We are aware that it is possible to observe artefacts or inclusions non-specific for $C$ trachomatis in stained slides. We would like to emphasise, however, that in our laboratory we stain the cultures using two methods: iodine and Giemsa stain modified by Johnson.' In addition, the isolation of $C$ trachomatis is supported by the results from a direct immunofluorescence method with monoclonal antibodies (Microtrak, Syva) performed by one of us in a double blind procedure. In our three cases all the results were in agreement, and thus we believe that the diagnosis of infection with $C$ trachomatis was correct. The emergence in Italy of strains of $C$ trachomatis resistant to tetracycline seems to us to be one of the possible explanations. This hypothesis is supported by a report by Cevenini et al, ${ }^{2}$ who observed that three strains of $C$ trachomatis exhibited a decreased sensitivity to chlortetracycline. ${ }^{2}$

We considered it to be important to report our data immediately, even in the absence of in vitro evidence. Furthermore, clinical observations of $C$ trachomatis infection have previously preceded laboratory evidence by many years. ${ }^{34}$ There was another important observation in our report, which Dr Taylor-Robinson seems to have overlooked. We reported an unusual transmission (by aerosol) of $C$ trachomatis. Therefore further research into routes of infection is needed to identify new classes of subjects at risk, such as dentists, and to recommend ways of preventing $C$ trachomatis infection.

Mario Midulla

Daniela Sollecito

FRANCO FELEPPA

ANNA Maria ASSENSIO STEFANO ILARI

Institute of Paediatrics,

La Sapienza University, and

CNR Institute Experimental Medicine,

Rome, Italy 00161
1 Johnson FWA. Comparison of staining techniques for demonstrating group A chlamydia in tissue culture. Medical Laboratory Technology 1975;32:233-8.

Laboratory Technology 1975;32:233-8.
2 Cevenini R, Landini MP, Doanti M, Rumpianesi F. Antimicrobial drug susceptibility of 15 strains of Chlamydia trachomatis recently isolated from cases of non gonococcal urethritis in Italy. F Antimicrob Chemother 1980;6:294-6.

3 Botsztejn A. Die pertussoïde, eosinophile Pneumonie des Säuglings. Annales Paediatrici 1941;157:28-46.

4 Schachter J, Lum L, Gooding CA, Ostler B. Pneumonitis following inclusion blennorrhea. F Pediatr 1975;87:779-80.

\section{Medical staffing and training in the West} Midlands region

SIR,-Dr J Parkhouse and colleagues (4 April, p 914) present data on future consultant needs derived from discussions with consultants in the West Midlands. Similar figures could be presented for other regions. The estimates are said to be the requirements for good patient care, and neither the question of funding nor the availability of junior staff was taken into account. The implications of some of the figures presented did not receive enough attention.

In specialties providing direct patient care and undertaking a considerable amount of emergency work the article shows that teams of four or five consultants can expect to have the support of one senior registrar, one registrar, and a variable number of senior house officers-four in paediatrics and obstetrics, two in medical and psychiatric specialties, and about one in the surgical specialties and anaesthetics.

The total number of hospital staff would be somewhat larger than at present without any dependence on overseas doctors, but clearly the distribution among the grades would be very different. The requirements for emergency cover set out in Hospital Medical Staffing: Achieving a Balance would not be met in these circumstances. The teams would also depend on those responsible for approving training posts agreeing to an even spread of posts throughout the region, which cannot be taken for granted.

The Joint Planning Advisory Committee bases many of its calculations on the future consultan requirements set out in regional strategic programmes. These programmes should reflect more than consultant views and include the arrangements for providing services and the costs of these. Consultant expansion is not taking place at the rate required to meet the figures presented from the West Midlands. This is largely because consultants do not see the service being appropriately provided by teams composed in the way that the article suggests and continue to undertake a traditional pattern of "consultant level" work, supported by a fairly large number of junı.

If strategic plans are not implemented there will be larger numbers of senior registrars and registrars unable to proceed in their training as smoothly as they have a right to expect. There is every reason to believe that junior doctors already accept the logic of the message, and this has resulted in the present difficulties in recruiting senior house officers in many surgical specialties and anaesthetics. The suggested need for a thorough reappraisal of the means of providing patient care is urgent.

North Western Regional Health Authority,

D H VAUGHaN

Manchester M60 7LP

\section{Hospital doctors' responsibility for prescribing}

SIR,-We note that the chief executive of the National Health Service Management Board, Mr Len Peach, has advised all his general managers that "The duty of prescribing for a particular element of a patient's treatment rests with the doctor who at the time has clinical responsibility for that element" (21 March, p 786). We believe that many share our unease about two points: firstly, that the hospital doctor should take over the provision of prescriptions for outpatients, and, secondly, that a particular doctor should prescribe not for the patient but for a "particular element" of his or her ill health. We believe that, as a general principle, prescriptions should be issued only by the patient's general practitioner. Of course there will be many exceptions on the grounds of urgency, patient convenience, and the fine titration of particularly toxic drugs or agents still on clinical trial. In general, however, the patient is referred to the outpatient department for an opinion, which his or her general practitioner may or may not accept and prescribe on.

General practitioners act as the only central referees for all prescriptions; their records show previous allergies and idiosyncrasies, and they are in the best position to prevent serious drug interactions and even the multiple prescription of the same basic drug under different names or in slightly varying forms, which is easily done with $\beta$ blockers and digitalis glycosides.

We believe that these considerations of patient safety and professional courtesy should continue to decide where a prescription is issued rather than the desirability of shifting prescribing costs from one part of the NHS to another.

J S WRIGHT

R J BIBBY

PJ HAYES

M S HENDY فे

P E T ISAACS

F I LEE N

J D MACKAY

J F O'ReIlly

Victoria Hospital,

Blackpool FY3 8NR

\section{c}

\section{Service hospitals}

SIR,-Scrutator seems to seek to raise doubts that the taxpayer is getting value for money out of the service hospitals (4 April, p 912). ${ }^{1} \mathrm{He}$ refers to "old arguments" about the special needs of the service hospitals to be prepared for war. Old arguments are not necessarily false arguments; indeed, their age may indicate their truth.

Preparedness for war entails more than general professional competence and breadth of experience. It requires a special knowledge of the management of the wounds and ills of war and of the circumstances of war in which that management is to be practised. It demands that the doctors, nurses, and support staff concerned have to be prepared, physically and mentally, to take their place at short notice in close support of the fighting services under operational conditions, with all the complexity and stress that that implies. If that close support does not come from service hospitals (and hospitals are people not buildings) where is it to come from? Which National Health Service hospitals are to take on the NATO commitment, and how and when are they to train for it?

Of course there should be sensible financial arrangements between the Ministry of Defence and the Department of Health, but let there be no doubt that the nation cannot afford to be without the hospitals of the defence medical servicespeople trained to meet a challenge that can arise very quickly, as we all saw just five years ago.

Cameron Moffat

Ministry of Defence,

London WCIV 6HE

National Audit Office. Ministry of Defence service hospitals. London: HMSO, 1987.

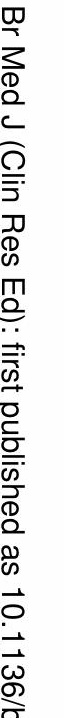 . ,
}

